Research Article

\title{
A comparative study of tranexamic acid and ethamsylate in menorrhagia
}

Nita K. Patel*, Manish R. Pandya

Department of Obstetrics and Gynecology, C.U. Shah Medical College \& Hospital, Surendranagar 363001, India

Received: 30 August 2012

Revised: 10 September 2012

Accepted: 16 September 2012

*Correspondence to:

Dr. Nita K. Patel,

E-mail: pcpatel27@gmail.com

\begin{abstract}
Background: Menorrhagia interferes with the woman's physical, social, emotional, and/or material quality of life. Antifibrinolytic drugs are effective in decreasing excessive menstrual bleeding. The objective of this study was to compare the effects of tranexamic acid and ethamsylate on quality of life in women with menorrhagia.

Methods: The 50 women with menorrhagia were randomised to receive either tranexamic acid or ethamsylate. Twenty five patients were allocated to receive tranexamic acid $500 \mathrm{mg}$ six hourly, and 25 patients to receive ethamsylate 500 mg six hourly. Among the parameters measured by the MIQ were impairment in social activities, work performance, physical activities, productivity, hygienic condition, psychological condition. Health-related quality-of-life question scores (MIQ scores) at baseline and after treatment were calculated as mean for tranexamic acid group and ethamsylate group.

Results: Tranexamic acid and ethamsylate treatment groups showed mean improvement in MIQ scores compared to baseline. However, the total mean score was higher in tranexamic acid group compared to ethamsylate group after three treatment cycles (21 Vs 17).

Conclusions: Use of tranexamic acid and ethamsylate improved health-related quality of life in patients with menorrhagia. Tranexamic acid showed better improvement in health-related quality of life compared to ethamsylate in patients with menorrhagia.
\end{abstract}

Keywords: Menorrhagia Impact Questionnaire (MIQ), Heavy menstrual bleeding, Antifibrinolytic, Dysfunctional uterine bleeding

\section{INTRODUCTION}

Menorrhagia quantitatively defined as menstrual blood loss of $80 \mathrm{~mL}$ or more per menstrual cycle, the diagnosis of heavy menstrual bleeding is typically based on personal perception of menstrual blood loss and its effect on daily life. ${ }^{1,2}$ Menorrhagia interferes with the woman's physical, social, emotional, and/or material quality of life.

The negative effects of menorrhagia on quality of life (e.g., limitations in daily activities, work performance, and social interactions) are what often lead women to seek medical treatment. ${ }^{3-6}$ Nonsteroidal antiinflammatory drugs, hormonal treatment and surgical procedures can effectively reduce menstrual blood loss; however, variable efficacy, relative contraindications, potential adverse effects, or undesired effects on fertility can limit the use of these therapies. ${ }^{7}$
Most patients complaining of menorrhagia have no detectable pelvic disease and are diagnosed as cases of dysfunctional uterine bleeding. The mechanisms controlling menstrual bleeding are poorly understood. In the past decade studies have shown increased endometrial fibrinolysis and an alteration in prostaglandin balance as local uterine abnormalities present in dysfunctional uterine bleeding. ${ }^{8,9}$

Antifibrinolytic drugs are effective in decreasing excessive menstrual bleeding. ${ }^{10}$ Tranexamic acid is a derivative of the amino acid lysine and having an antifibrinolytic action that competitively inhibits the activation of plasminogen to plasmin, a molecule responsible for the degradation of fibrin. The haemostatic Ethamsylate have also been widely used to control excessive menstrual bleeding. ${ }^{11}$ Ethamsylate is believed to work by increasing capillary endothelial resistance and promoting platelet adhesion. It also inhibits biosynthesis 
and action of those prostaglandins which cause platelet disaggregation, vasodilation and increased capillary permeability.

The objective of this study was to compare the effects of tranexamic acid and ethamsylate on quality of life in women with menorrhagia.

\section{METHODS}

From May 2011 to July 2011, women attending the gynecological clinic at C.U. Shah Medical College \& Hospital, aged 18-45 with complaint of menorrhagia and no history of systemic disease such as platelet disorder or coagulopathies related to menorrhagia, previous history of thromboembolic disease, renal or hepatic impairment and acquired disturbances of color vision, pregnancy and no concomitant use of oral contraceptives were recruited into this study.

The 50 women with menorrhagia were randomised to receive either tranexamic acid or ethamsylate. They were allocated by a computer generated randomisation list to one of the two treatments taken for five days from day 1 of bleeding during the three subsequent menstrual periods. Twenty five patients were allocated to receive tranexamic acid $500 \mathrm{mg}$ six hourly, and 25 patients to receive ethamsylate $500 \mathrm{mg}$ six hourly. The study was approved by Institutional Ethics Committee and was conducted in compliance with the principles of the Declaration of Helsinki and guidelines for Good Clinical Practice. All participants provided signed informed consent.

Table 1: Menorrhagia Impact Questionnaire (MIQ).

\begin{tabular}{|c|c|}
\hline Questions & Response Options \\
\hline $\begin{array}{l}\text { 1. Do you feel that your social activities have been impaired } \\
\text { because of your menstrual bleeding? }\end{array}$ & $\begin{array}{l}\text { 1. Extremely } \\
\text { 2. Quite a bit } \\
\text { 3. Moderately } \\
\text { 4. Slightly } \\
\text { 5. Not at all }\end{array}$ \\
\hline $\begin{array}{l}\text { 2. Do you feel that your work performance has been impaired } \\
\text { because of your menstrual bleeding? }\end{array}$ & $\begin{array}{l}\text { 1. Extremely } \\
\text { 2. Quite a bit } \\
\text { 3. Moderately } \\
\text { 4. Slightly } \\
\text { 5. Not at all }\end{array}$ \\
\hline $\begin{array}{l}\text { 3. Do you feel tired or exhausted because of your menstrual } \\
\text { bleeding? }\end{array}$ & $\begin{array}{l}\text { 1. Extremely } \\
\text { 2. Quite a bit } \\
\text { 3. Moderately } \\
\text { 4. Slightly } \\
\text { 5. Not at all }\end{array}$ \\
\hline 4. Do you feel less productive during menstruation? & $\begin{array}{l}\text { 1. Extremely } \\
\text { 2. Quite a bit } \\
\text { 3. Moderately } \\
\text { 4. Slightly } \\
\text { 5. Not at all }\end{array}$ \\
\hline 5. Do you feel unclean or unhygienic during menstrual bleeding? & $\begin{array}{l}\text { 1. Extremely } \\
\text { 2. Quite a bit } \\
\text { 3. Moderately } \\
\text { 4. Slightly } \\
\text { 5. Not at all }\end{array}$ \\
\hline 6. Do you feel depressed during menstrual bleeding? & $\begin{array}{l}\text { 1. Extremely } \\
\text { 2. Quite a bit } \\
\text { 3. Moderately } \\
\text { 4. Slightly } \\
\text { 5. Not at all }\end{array}$ \\
\hline
\end{tabular}

The end points included change from baseline in healthrelated quality-of-life parameters. Qualitative healthrelated quality-of-life assessments were based on responses to the Menorrhagia Impact Questionnaire
(MIQ) that was completed by participants after initial screening and treatment cycles (Table 1). Among the parameters measured by the MIQ were impairment in social activities, work performance, physical activities, productivity, hygienic condition, psychological condition. 
The MIQ was scored on a 1 to 5 point scale (1: Extremely; 5: Not at all). ${ }^{12,13}$ Health-related quality-of-life question scores (MIQ scores) at baseline and after treatment were calculated as mean for tranexamic acid group and ethamsylate group.

\section{RESULTS}

A total of 50 patients were randomized to receive tranexamic acid $(n=25)$ or ethamsylate $(n=25)$. Both groups had comparable baseline and demographic characteristics. There was mean improvement in MIQ score for social activities related question in both treatment groups compared to baseline (Figure 1). For work performance related question, there was mean improvement in tranexamic acid group compared to baseline. But there was no change in MIQ score for ethamsylate group compared to baseline in work performance related question (Figure 2). There was mean improvement in MIQ scores for tiredness, productiveness, hygienic condition and depressiveness related questions in both treatment groups compared to baseline (Figure 3-6).

Overall, both treatment groups showed mean improvement in MIQ scores compared to baseline (Table 2). However, the total mean score was higher in tranexamic acid group compared to ethamsylate group after three treatment cycles (21 Vs 17).

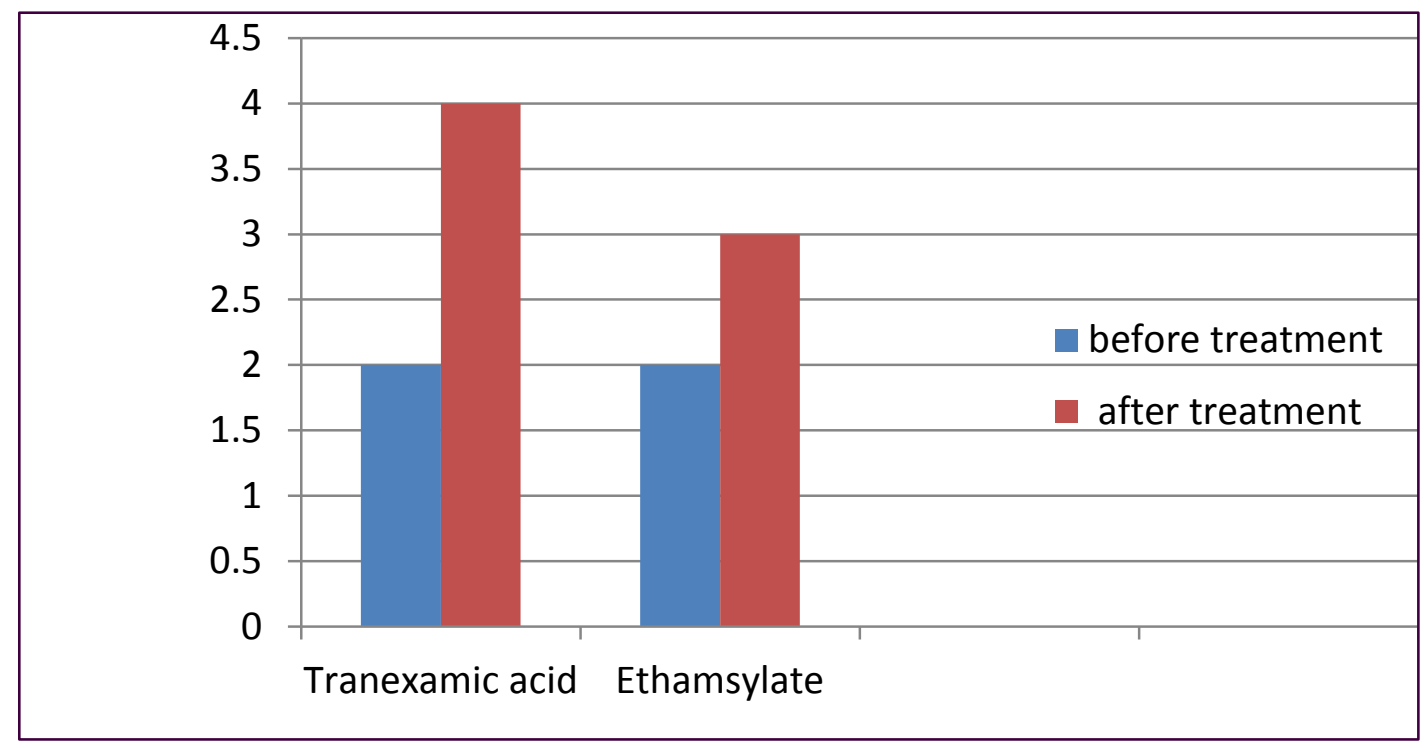

Figure 1: Effects of tranexamic acid and ethamsylate on mean score- social activities.

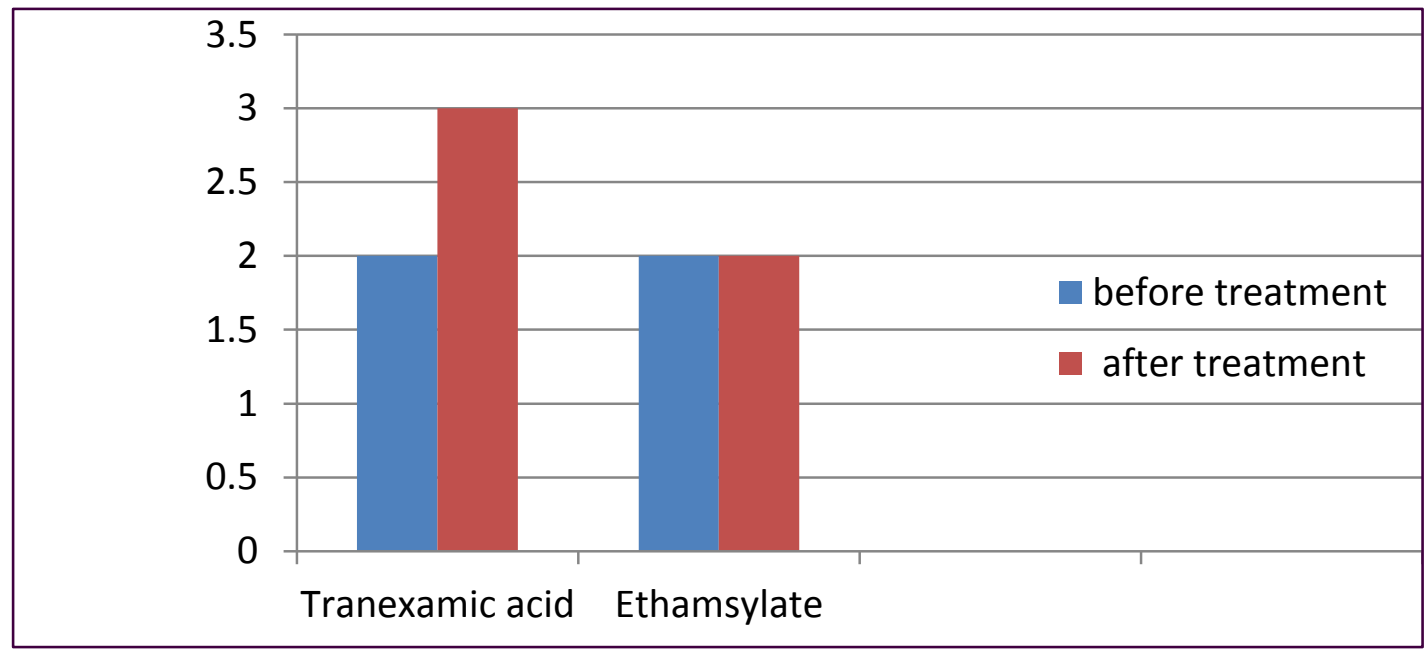

Figure 2: Effects of tranexamic acid and ethamsylate on mean score- work performance. 


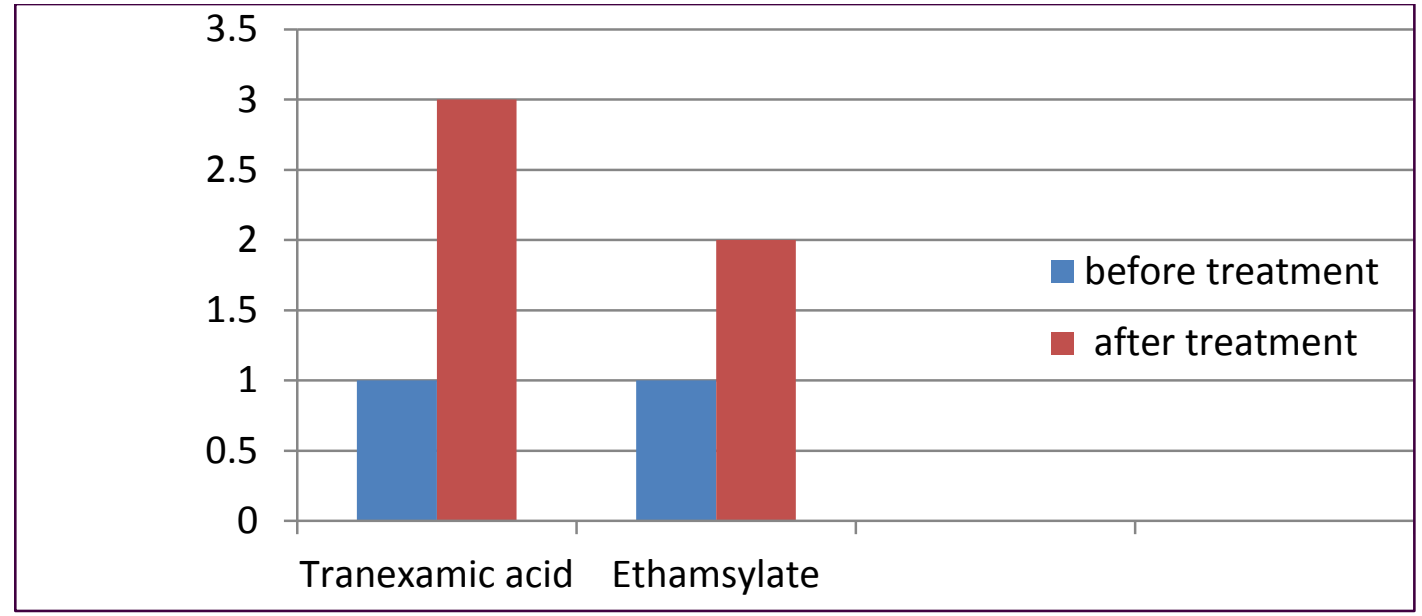

Figure 3: Effects of tranexamic acid and ethamsylate on mean score- tired or exhausted.

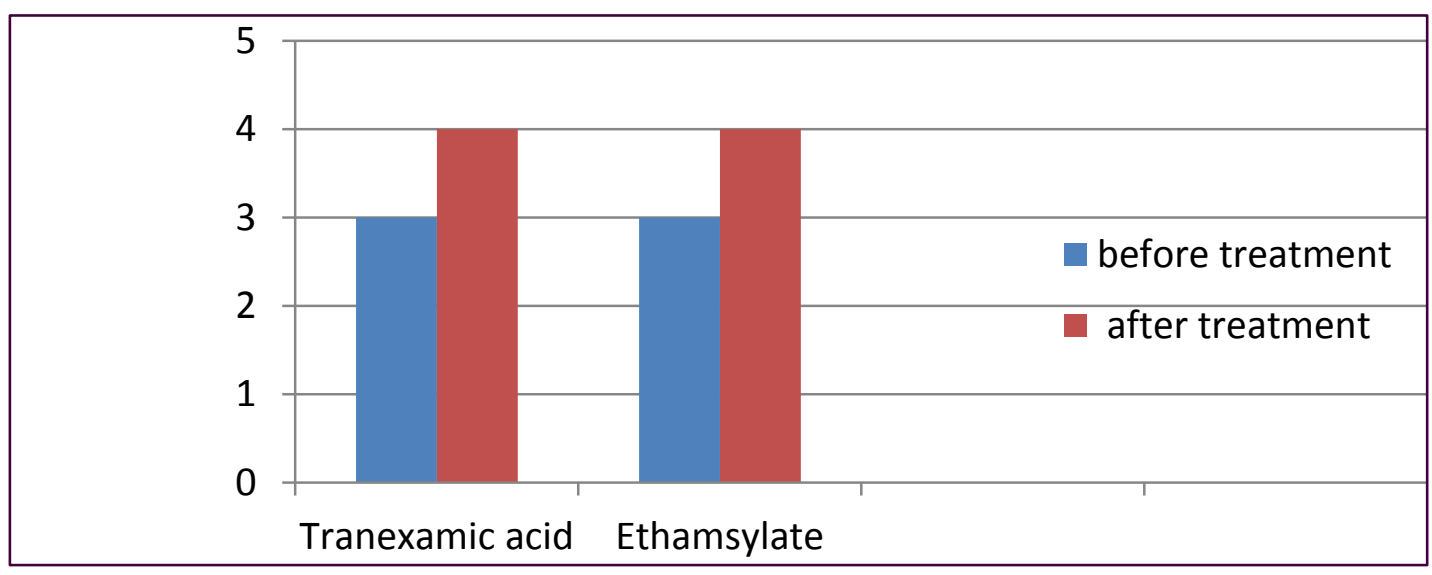

Figure 4: Effects of tranexamic acid and ethamsylate on mean score- productive.

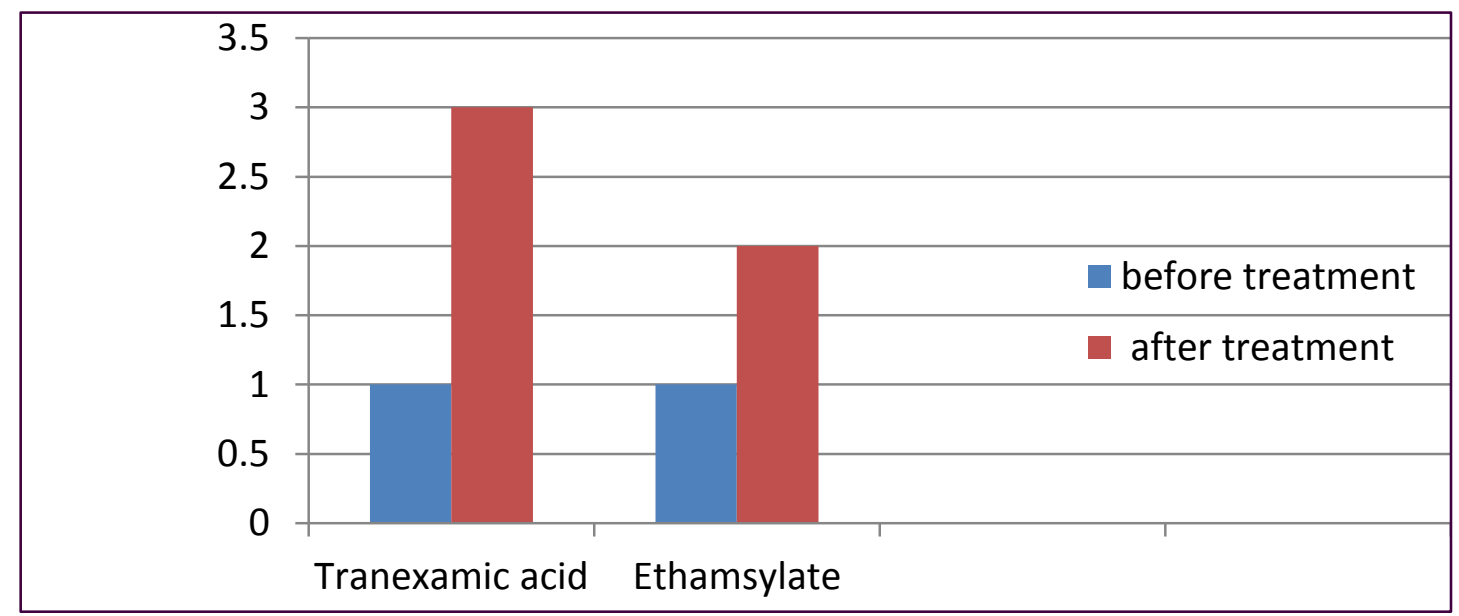

Figure 5: Effects of tranexamic acid and ethamsylate on mean score- unclean or unhygienic. 


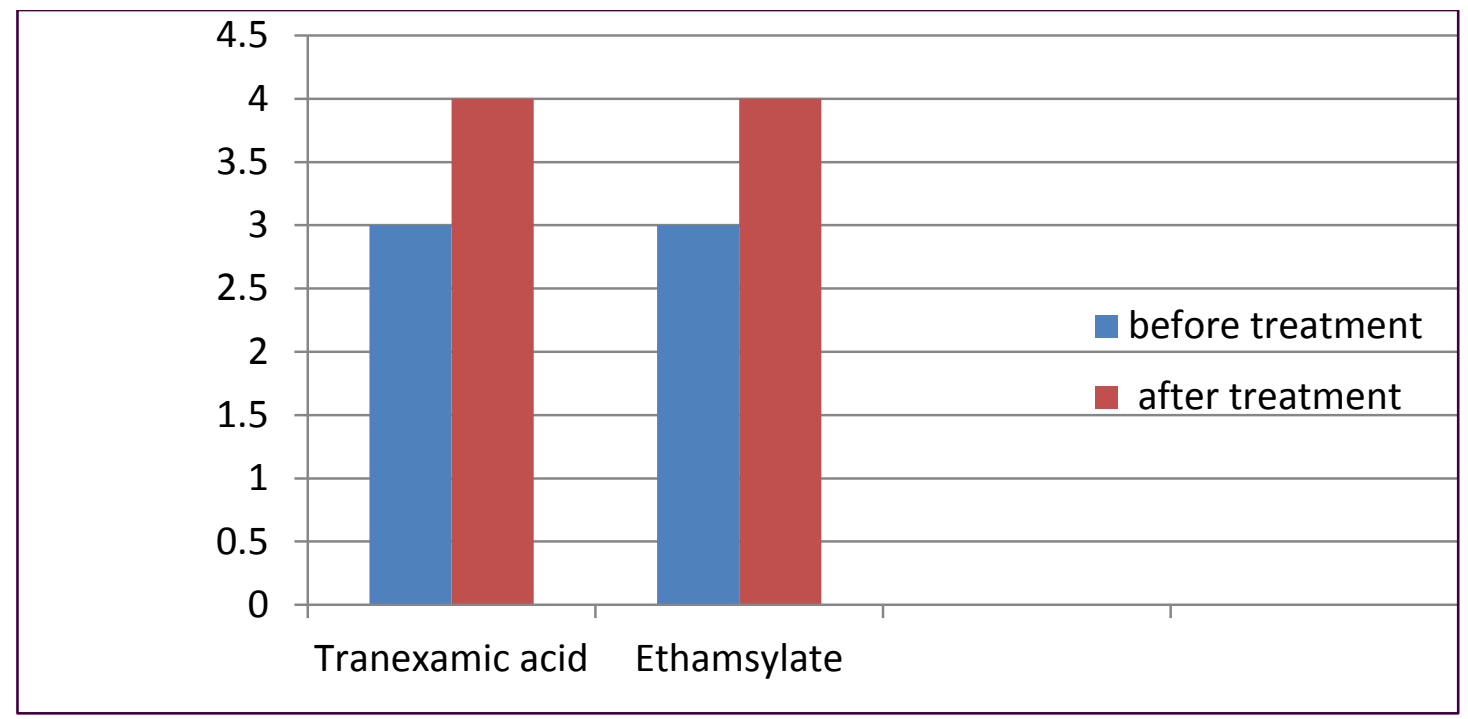

Figure 6: Effects of tranexamic acid and ethamsylate on mean score- depressed.

Table 2: Effects of tranexamic acid and ethamsylate on mean scores.

\begin{tabular}{|ccccc|}
\hline Questions & Before & \multicolumn{2}{c|}{ MIQ Scores } \\
treatment & After treatment \\
Social activities & 2 & 4 & Ethamsylate \\
Work performance & 2 & 3 & 3 \\
Tired / Exhausted & 1 & 3 & 2 \\
Feeling productive & 3 & 4 & 2 \\
Unclean / & 1 & 3 & 4 \\
unhygienic & 3 & 4 & 4 \\
Depressed & 12 & 21 & 17 \\
Total & & 9 & 5 \\
Difference & & & 2 \\
\hline
\end{tabular}

\section{DISCUSSION}

In this study, tranexamic acid and ethamsylate provided qualitative relief for women with menorrhagia. Moreover, women receiving tranexamic acid reported more improvements in health-related quality-of-life parameters compared with those receiving ethamsylate.

Quantitative measurements of menstrual blood loss used in clinical trials are typically not practical in routine clinical care, as women are required to collect and return all menses captured on sanitary products for laboratory analysis. Previous studies had suggested that tranexamic acid improves health-related quality of life in women with heavy menstrual bleeding. ${ }^{13-16}$
In women with menorrhagia, tranexamic acid appears to stabilize the deposition of endometrial vascular wall fibrin that occurs with menstruation, ${ }^{17}$ but is unlikely to increase thrombosis. Thrombosis has not been observed in men or women receiving tranexamic acid for the management of bleeding secondary to cardiac or oral surgery, acute upper gastrointestinal bleeding, or ocular trauma,${ }^{17}$ and the use of tranexamic acid is not associated with an increased risk or incidence of thromboembolic events compared with the background rate of thrombotic events in women of childbearing age. ${ }^{18,19}$

Methodological limitations in the present study include the small sample size and the absence of blinding. Randomized controlled trials with larger numbers are 
needed to compare the antifibrinolytics to other medical therapies. Other limitation of the study was the prohibition of certain medications during the entire study period (e.g., hormonal contraceptives) or during the women's menstrual cycle (e.g., nonsteroidal antiinflammatory drugs) to avoid potential confounding effects on menstrual blood loss or adverse events. Additional data are needed to determine whether concomitant use of these medications with tranexamic acid would influence the risk of certain adverse events.

In the present study, use of tranexamic acid and ethamsylate improved health-related quality of life. Tranexamic acid showed better improvement in healthrelated quality of life compared to ethamsylate. Tranexamic acid offers a first-line, nonhormonal, nonsurgical treatment option for women with menorrhagia that may become an important alternative to surgical procedures and medical treatments.

\section{REFERENCES}

1. Hallberg L, Hogdahl AM, Nilsson L, Rybo G. Menstrual blood loss: a population study. Variation at different ages and attempts to define normality. Acta Obstet Gynecol Scand 1966;45:320-51.

2. Wyatt KM, Dimmock PW, Walker TJ, O'Brien PM. Determination of total menstrual blood loss. Fertil Steril 2001;76:125-31.

3. Shapley M, Jordan K, Croft PR. Why women consult with increased vaginal bleeding: a casecontrol study. Br J Gen Pract 2002;52:108-13.

4. Liu Z, Doan QV, Blumenthal P, Dubois RW. A systematic review evaluating health-related quality of life, work impairment, and health-care costs and utilization in abnormal uterine bleeding. Value Health 2007; 10:183-94.

5. Shankar M, Chi C, Kadir RA. Review of quality of life: menorrhagia in women with or without inherited bleeding disorders. Haemophilia 2008;14:15-20.

6. Coulter A, Peto V, Jenkinson C. Quality of life and patient satisfaction following treatment for menorrhagia. Fam Pract 1994;11:394-401.

7. Hurskainen R, Grenman S, Komi I, Kujansuu E, Luoto R, Orrainen M, et al. Diagnosis and treatment of menorrhagia. Acta Obstet Gynecol Scand 2007;86:749-57.
8. Smith SK, Abel MH, Kelly RW, Baird DT Prostaglandins and dysfunctional uterine bleeding. Research and Clinical Forums 1983;5:39-43.

9. Sheppard BL. The pathology of dysfunctional uterine bleeding. Clin Obstet Gynecol 1984;11:22738.

10. Nilsson L, Rybo G. Treatment of menorrhagia with an Antifibrinolytic agent, tranexamic acid. Acta Obstet Gynecol Scand 1967;46:572-80.

11. Chamberlain G, Freeman R, Price F, Kennedy A, Green D, Eve L. A comparative study of ethamsylate and mefenamic acid in dysfunctional uterine bleeding. Br J Obstet Gynaecol 1991;98: 707-10.

12. Freeman EW, Lukes A, VanDrie D, Mabey RG, Gersten J, Adomako TL. A dose-response study of a novel, oral tranexamic formulation for heavy menstrual bleeding. Am J Obstet Gynecol. 2011;205(4):319.e1-7.

13. Lukes AS, Moore KA, Muse KN. Tranexamic acid treatment for heavy menstrual bleeding: A randomized controlled trial. Obstet Gynecol. 2010;116(4):865-875.

14. Winkler UH. The effect of tranexamic acid on the quality of life of women with heavy menstrual bleeding. Eur J Obstet Gynecol Reprod Biol 2001;99:238-43.

15. Kouides PA, Byams VR, Philipp CS, Stein SF, Heit JA, Lukes AS, et al. Multisite management study of menorrhagia with abnormal laboratory haemostasis: a prospective crossover study of intranasal Desmopressin and oral tranexamic acid. $\mathrm{Br} \mathrm{J}$ Haematol 2009;145:212-20.

16. Srinil S, Jaisamrarn U. Treatment of idiopathic menorrhagia with tranexamic acid. J Med Assoc Thai. 2005 Oct;88 Suppl 2:S1-6.

17. Wellington K, Wagstaff AJ. Tranexamic acid: a review of its use in the management of menorrhagia. Drugs 2003;63:1417-33.

18. Berntorp E, Follrud C, Lethagen S. No increased risk of venous thrombosis in women taking tranexamic acid. Thromb Haemost 2001;86:714-5.

19. Lindoff C, Rybo G, Astedt B. Treatment with tranexamic acid during pregnancy, and the risk of thrombo-embolic complications. Thromb Haemost 1993;70:238-40. 